\title{
Haemagglutination by the Bacteroides fragilis group
}

\author{
WILLEMIEN A. C. VEL, F. NAMAVAR, A. MARIAN, \\ J. J. VERWEIJ-VAN VUGHT, ANJA N. B. PUBBEN and D. M. MACLAREN
}

Research Group for Commensal Infections, Departments of Medical and Oral Microbiology, Vrije Universiteit, P.O. Box 7161, 1007 MC Amsterdam, The Netherlands

\begin{abstract}
Summary. Adhesive properties of five species of Bacteroides were compared by direct haemagglutination with erythrocytes of different origin. Only strains of Bacteroides fragilis agglutinated erythrocytes and different patterns of haemagglutination were observed. None of eight carbohydrates tested inhibited haemagglutination. The activity was destroyed by heat and by periodate treatment, but not by three proteases tested.
\end{abstract}

\section{Introduction}

Adherence to epithelial surfaces is considered to be a prerequisite for the pathogenicity of most bacteria. Bacteria attach themselves to host cells by many surface structures such as fimbriae, fibrils, lipopolysaccharides or capsular polysaccharides, glycocalices or other exopolymers (Gibbons, 1977).

In gram-negative anaerobes of the genus Bacteroides many surface structures have been described which mediate attachment (Onderdonk et al., 1978; Okuda et al., 1981). Capsule-like outer surface layers as well as pilus-like threads are described in black pigmented species (Woo et al., 1979), and surface differences between these species could account for differences in adherence to mammalian cells. Of the saccharolytic intestinal species of Bacteroides, $\boldsymbol{B}$. fragilis is most often found in clinical infections but is relatively uncommon in the normal colonic microflora (Finegold, 1977). This greater virulence is often attributed to the presence of a capsule, identified by light-microscopy and electronmicroscopy (Babb and Cummins, 1978; Burt et al., 1978; Kasper et al., 1979; Patrick et al., 1984), which promotes attachment (Onderdonk et al., 1978). Extracted capsular material produces abscesses in rats (Onderdonk et al., 1977). Less virulent species may also have capsules (Babb and Cummins, 1978; Burt et al., 1978; Brook et al., 1984) so the relation between capsule and virulence is not clear. Recently, pili have been demonstrated in some non-capsulated strains of $B$. fragilis which attach more easily to epithelial cells, erythrocytes and phagocytes (Pruzzo et al., 1984). In the present study adhesive properties of different species of

Received 8 Mar. 1985; accepted 5 May 1985.
Bacteroides were compared by direct haemagglutination with erythrocytes of different origins.

\section{Materials and methods}

\section{Bacteria}

The strains of Bacteroides examined were isolated from infected patients in the Hospital of the Vrije Universiteit in Amsterdam, identified with Minitek (BBL, Becton Dickinson and Co., USA), and maintained in $30 \%$ glycerol at $-70^{\circ} \mathrm{C}$. The strains were grown in Wilkins Chalgren Anaerobic Broth (Oxoid) at $37^{\circ} \mathrm{C}$ in an anaerobic chamber with an atmosphere of $\mathrm{N}_{2} 85 \%, \mathrm{H}_{2} 10 \%$ and $\mathrm{CO}_{2} 5 \%$. The cells were centrifuged after $18 \mathrm{~h}$ and gently resuspended in phosphate buffered saline (PBS) to a concentration of $c .5 \times 10^{9}$ bacteria $/ \mathrm{ml}$, as estimated by optical density.

\section{Erythrocytes}

Human $\mathrm{A}^{+}$, horse, sheep, guinea pig and chicken erythrocytes were harvested from defibrinated blood by centrifugation and washed three times with PBS. A suspension $(2 \% \mathrm{v} / \mathrm{v})$ of the packed cells obtained by centrifugation for $10 \mathrm{~min}$ at $100 \mathrm{~g}$ in PBS was used in the haemagglutination studies. For tannic acid treatment, equal volumes of washed sheep erythrocytes $3 \% \mathrm{v} / \mathrm{v}$ and tannic acid (BDH Chemicals Ltd) $0.01 \% \mathrm{w} / \mathrm{v}$ in PBS were mixed, incubated at $37^{\circ} \mathrm{C}$ for $15 \mathrm{~min}$, washed thrice and resuspended in PBS to $2 \% \mathrm{v} / \mathrm{v}$.

\section{Haemagglutination}

Haemagglutination was tested qualitatively by mixing $0.05 \mathrm{ml}$ of the bacterial suspension with $0.05 \mathrm{ml}$ of the erythrocytes on ceramic ring slides (Clay Adams, USA) for $5 \mathrm{~min}$. When the qualitative test gave positive results, a quantitative test was performed. Serial twofold dilutions 
of the bacterial suspension in $0.01-\mathrm{ml}$ volumes were made in a Multiwell Disposo-tray (Libro Division, Flow Laboratories Inc., USA) with a well capacity of $1 \mathrm{ml}$. To each well $0.1 \mathrm{ml}$ of the erythrocyte suspension was added. After shaking for $5 \mathrm{~min}$ at room temperature the trays were kept overnight at $4^{\circ} \mathrm{C}$ and haemagglutination was read the next morning. Autoagglutination of the bacteria was examined by mixing them with PBS instead of erythrocytes.

The ability of eight carbohydrates-D-mannose, Darabinose, D-glucose, D-galactose, D-fructose, D-xylose, D-ribose and D-glucosamine- to inhibit the agglutination of the various erythrocytes by strains of $B$. fragilis was examined by mixing $0.01 \mathrm{ml}$ of $0.22 \mathrm{M}$ solutions of the different carbohydrates in PBS and $0.02 \mathrm{ml}$ of the bacterial suspension on a ceramic ring slide. The result was compared with a control without carbohydrate.

Haemagglutination of $B$. fragilis strains BE1, BE4, BE12 and BE31 with chicken erythrocytes was tested after treatment of the bacteria with heat, proteases or $\mathrm{NaIO}_{4}$. For heat treatment the bacterial suspension was heated for $1 \mathrm{~h}$ at $100^{\circ} \mathrm{C}$, centrifuged and resuspended in PBS to the original volume. For protease treatment $1 \mathrm{ml}$ of the bacteria were centrifuged and resuspended in $1 \mathrm{ml}$ of Tris-buffered saline-50 mM Tris (Merck, Darmstadt, W. Germany), $50 \mathrm{~mm} \mathrm{NaCl}, p \mathrm{H} 8 \cdot 0$-with Trypsin (Flow Laboratories, Irvine, Scotland), Proteinase K (Merck) or Pronase P (Serva, Heidelberg, W. Germany), each $50 \mathrm{mg} /$ $L$, as a control, with no enzyme. The suspensions were incubated at $37^{\circ} \mathrm{C}$ in a shaking waterbath, and centrifuged after $30 \mathrm{~min}$. The pellets were resuspended in PBS to the original volume.

For $\mathrm{NaIO}_{4}$ treatment $1 \mathrm{ml}$ of the bacterial suspension was centrifuged and the pellet resuspended in distilled water with $0.1,0.01$ or $0.001 \mathrm{M} \mathrm{NaIO}_{4}$ (Merck) or, as a control, no periodate. The suspensions were shaken at room temperature for $30 \mathrm{~min}$, then an equal volume of glycerin (Merck) was added to reduce the remaining periodate. The cells were centrifuged and resuspended in the original volume of PBS.

Haemagglutination was estimated qualitatively on ceramic ring slides and compared with that of untreated bacteria.

\section{Results}

None of the strains of the species other than $B$. fragilis - seven strains of $B$. distasonis, five strains of $B$. thetaiotaomicron, nine strains of $B$. ovatus and eight strains of $B$. vulgatus - agglutinated any of the species of erythrocyte tested. For all strains this observation was confirmed in at least six experiments. With the strains of $B$. fragilis different patterns of haemagglutination were found, as shown in the table. One group of three strains agglutinated none of the erythrocytes tested. Two strains agglutinated only chicken and tanned sheep erythrocytes. Eleven strains agglutinated all erythrocytes tested to various degrees. Agglutination of chicken and tanned sheep erythrocytes was most marked; the mean number of bacteria required for their agglutination was $2.0 \times 10^{8} / \mathrm{ml}$. For agglutination of human and guinea-pig erythrocytes a mean of $4.8 \times 10^{8}$ bacteria $/ \mathrm{ml}$ was needed, for sheep erythrocytes $7 \times 10^{8}$ bacteria $/ \mathrm{ml}$, and for horse erythrocytes, and four strains agglutinated chicken and tanned and normal sheep erythrocytes but not one or two of the other types. Three strains (BE38, BE54 and BE56) autoagglutinated in PBS.

Haemagglutination by $B$. fragilis strains BE1, BE3, BE12, BE25A, BE25B and BE31 was not inhibited by any of 8 carbohydrates present in a concentration of $0.055 \mathrm{M}$. Heat treatment of $B$.

Table. Haemagglutination of erythrocytes of different origin by strains of $B$. fragilis

\begin{tabular}{|c|c|c|c|c|c|}
\hline \multirow[b]{2}{*}{ B. fragilis strain } & \multicolumn{5}{|c|}{ Agglutination of erythrocytes* } \\
\hline & $\begin{array}{c}\text { Chicken and tanned } \\
\text { sheep }\end{array}$ & human & sheep & horse & guinea pig \\
\hline BE 15, BE 17, BE $25 \mathrm{C}$ & - & - & - & - & - \\
\hline BE 12, BE 26 & ++ & - & - & - & - \\
\hline $\begin{array}{l}\text { BE } 43 \text { B, BE } 45, \text { BE } 49, \text { BE } 61 \text {, BE } 64 \\
\text { BE } 2, \text { BE } 3, \text { BE } 13, \text { BE } 43 \text { A, BE } 59 \\
\text { BE } 4\end{array}$ & +++ & ++ & $H+$ & ++ & ++ \\
\hline BE 19, BE 21, BE 31, BE 48, BE 55, BE 57 & +++ & ++ & ++ & - & ++ \\
\hline BE 1 & ++ & ++ & ++ & ++ & - \\
\hline BE $25 \mathrm{~B}$ & ++ & ++ & ++ & - & - \\
\hline BE $25 \mathrm{~A}$ & ++ & - & ++ & - & + \\
\hline
\end{tabular}

* $-=$ No agglutination with $2.5 \times 10^{9} \mathrm{bacteria} / \mathrm{ml} ;+=2.5 \times 10^{4}$ bacteria $/ \mathrm{ml} \mathrm{required} \mathrm{for} \mathrm{haemaggluti-}$ nation; $++\left(2.5 \times 10^{8}\right)-\left(2.5 \times 10^{9}\right)$ bacteria/ml required; $+++=<2.5 \times 10^{8}$ bacteria/ml required. 
fragilis strains BE1, BE4, BE12 and BE31 destroyed all haemagglutinating activity. Treatment of these four strains with trypsin, proteinase $\mathrm{K}$ or pronase $\mathrm{P}$ had no effect but treatment with periodate had an effect, which could not be attributed to incubation in distilled water because the controls agglutinated as well as the untreated bacteria. The haemagglutinating activity of all strains was destroyed by $0 \cdot 1 \mathrm{M}$ periodate, of strains BE1, BE4 and BE 12 by $0.01 \mathrm{M}$, and of strain BE1 alone by $0.001 \mathrm{M}$.

\section{Discussion}

In 1984 Pruzzo et al. described haemagglutination and adhesion to other mammalian cells of 12 strains of $B$. fragilis which they found to be noncapsulate by light microscopy with India Ink. These strains, however, possessed pili to which adhesion was attributed. Riley and Mee (1984) reported an absolute correlation between capsulation (determined with India Ink wet preparations) and haemagglutination in 50 strains of $B$. fragilis; pili were not observed in haemagglutinating strains. The present report is the first describing haemagglutination by many strains of $B$. fragilis but not by strains of other closely related species. B. fragilis has been reported to be the most pathogenic species of the group (Finegold, 1977) and adhesion could be an important virulence factor.

\section{REFERENCES}

Babb J L, Cummins C S 1978 Encapsulation of Bacteroides species. Infection and Immunity 19:1088-1091.

Brook I, Coolbaugh J C, Walker R I 1984 Pathogenicity of piliated and encapsulated Bacteroides fragilis. European Journal of Clinical Microbiology 3:207-209.

Burt S, Meldrum S, Woods D R, Jones D T 1978 Colonial variation, capsule formation and bacteriophage resistance in Bacteroides thetaiotaomicron. Applied and Environmental Microbiology 35:439-443.

Finegold S M 1977 Anaerobic bacteria in human disease. Academic Press, New York.

Gibbons R J 1977 Adherence of bacterial to host tissue. In: Schlessinger D (ed) Microbiology - 1977, American Society for Microbiology, Washington DC, pp. 395-406.

Kasper D L, Onderdonk A B, Polk B F, Bartlett J G 1979 Surface antigens as virulence factors in infection with Bacteroides fragilis. Reviews of Infectious Diseases 1:278-290.

Lambe D W, Mayberry-Carson K J, Ferguson K P, Costerton J W 1984 Morphological stabilization of the glycocalyces of 23 strains of five Bacteroides species using specific antisera. Canadian Journal of Microbiology 30:809-819.

Okuda K, Slots J, Genco R J 1981 Bacteroides gingivalis, Bacteroides asaccharolyticus and Bacteroides melaninogeni-
The relation between surface structures and haemagglutination in the $B$. fragilis group is uncertain. This may result from the limitations of the technique used to examine surface structures. Studying the cells of our strains in India Ink smears, counterstained with fuchsin (Merck, $0.2 \%$ aqueous solution), we saw clear zones around all cells of all strains, whether haemagglutinating or not. When India Ink wet mounts were examined by phase contrast microscopy there was great variation between cells, not only of different species or strains, but even within one culture. The problems encountered in electronmicroscopy have been discussed by Lambe et al. (1984). We cannot, from our results, relate structure to haemagglutinating activity. The results of experiments in which we tried to inhibit haemagglutination with sugars (the method used to inhibit the lectin-like binding of enterobacterial pili to sugar residues on mammalian cells), with proteinases (which should break down protein adhesins) and with $\mathrm{NaIO}_{4}$ (which oxidises polysaccharide outer-surface structures), favour the hypothesis that polysaccharide structures are responsible for the haemagglutination. The fact that different patterns of haemagglutination were found with the set of erythrocytes used, suggests that more than one adhesin might be implicated.

cus subspecies: cell surface morphology and adherence to erythrocytes and human buccal epithelial cells. Current Microbiology 6:7-12.

Onderdonk A B, Kasper D L, Cisneros R L, Bartlett J G 1977 The capsular polysaccharide of Bacteroides fragilis as a virulence factor: comparison of the pathogenic potential of encapsulated and unencapsulated strains. Journal of Infectious Diseases 136:82-89.

Onderdonk A B, Moon N E, Kasper D L, Bartlett J G 1978 Adherence of Bacteroides fragilis in vivo. Infection and Immunity 19:1083-1087.

Patrick S, Reid J H, Larkin M J 1984 The growth and survival of capsulate and non-capsulate Bacteroides fragilis in vivo and in vitro. Journal of Medical Microbiology 17:237-246.

Pruzzo C, Danielli B, Ricchetti M 1984 Piliated Bacteroides fragilis strains adhere to epithelial cells and are more sensitive to phagocytosis by human neutrophils than nonpiliated strains. Infection and Immunity 43:189-194.

Riley T V, Mee B J 1984 Haemagglutination of Bacteroides fragilis. FEMS Microbiology Letters 25:229-232.

Woo D D L, Holt S C, Leadbetter E R 1979 Ultrastructure of Bacteroides species: Bacteroides asaccharolyticus, Bacteroides fragilis, Bacteroides melaninogenicus subspecies melaninogenicus and Bacteroides melaninogenicus subspecies intermedius. Journal of Infectious Diseases 139:534-546. 